\title{
C-reactive protein on postoperative day 3 as a predictor of infectious complications following gastric cancer resection
}

\author{
Yuji Shishido $\cdot$ Kazumasa Fujitani • \\ Kazuyoshi Yamamoto • Motohiro Hirao • \\ Toshimasa Tsujinaka $\cdot$ Mitsugu Sekimoto
}

Received: 25 August 2014/Accepted: 15 December 2014/Published online: 6 January 2015

(c) The International Gastric Cancer Association and The Japanese Gastric Cancer Association 2015

\begin{abstract}
Background Postoperative infectious complications (PICs) after gastric cancer resection remain a clinically relevant problem. Early detection of PICs, before critical illness develops, may be of considerable clinical benefit. The aims of this study were to investigate the predictive factors for PICs and to define the clinical parameters for detecting them early in patients with gastric cancer resection.

Methods Clinical data for 417 consecutive patients undergoing elective gastrectomy for primary gastric cancer between 2009 and 2012 were retrospectively analyzed. Diagnostic accuracy was determined by the area under the receiver operating characteristic curve (AUC). Univariate and multivariate logistic regression analyses identified clinical factors predicting PICs of grade III or more according to the Clavien-Dindo classification.

Results Forty-four patients developed PICs of grade $\geq$ III [10.6\%, $95 \%$ confidence interval (CI) 7.6-13.5\%]. As a systemic inflammatory marker, C-reactive protein (CRP) on postoperative day (POD) 3 had superior diagnostic accuracy for PICs (AUC 0.802, $95 \%$ CI 0.735-0.870) with a calculated cutoff value of $17.7 \mathrm{mg} / \mathrm{dl}$, yielding a
\end{abstract}

Y. Shishido $\cdot$ K. Yamamoto $\cdot$ M. Hirao $\cdot$ M. Sekimoto

Department of Surgery, Osaka National Hospital, Osaka, Japan

K. Fujitani $(\bowtie)$

Department of Surgery, Osaka Prefectural General Medical

Center, 3-1-56 Bandaihigashi, Sumiyoshi-ku, Osaka 558-8558,

Japan

e-mail: fujitani@gh.opho.jp

T. Tsujinaka

Department of Surgery, Kaizuka City Hospital, Kaizuka, Osaka, Japan sensitivity of 0.66 (95\% CI $0.524-0.774)$ and a specificity of 0.84 (95\% CI 0.821-0.850). Multivariate analysis identified CRP on POD 3 of $17.7 \mathrm{mg} / \mathrm{dl}$ or greater [odds ratio (OR) 8.094, $95 \%$ CI 3.568-19.342) as well as clinical stage $\geq$ II (OR 4.445, $95 \%$ CI 1.478-15.881) and operation time $\geq 250 \mathrm{~min}$ (OR 3.638, $95 \%$ CI 1.449-10.137) as significant predictive factors for PICs after gastrectomy. Conclusions Elevated CRP levels on POD 3 will help physicians predict the postoperative course and facilitate decision-making regarding prompt, comprehensive clinical searches and therapeutic approaches for PICs.

Keywords C-reactive protein - Postoperative infectious complications · Gastric cancer

\section{Introduction}

Gastric cancer is the fourth most common malignancy worldwide, and the second leading cause of cancer-related death $[1,2]$. Although surgical resection provides the only possibility of cure in patients with gastric cancer, postoperative complications remain a clinically relevant problem [3] despite improvements in surgical procedures and perioperative care after gastric cancer surgery. Following resection of gastric cancer, overall morbidity and mortality rates have been reported to be $17.4-24.5 \%$ and $0.6-0.8 \%$, respectively, in East Asia [4-6], while higher overall morbidities of $13.6-46 \%$ and mortalities of $0.6-13 \%$ have been demonstrated after radical gastrectomy in the West [7-11]. In particular, infectious complications are the most common cause of postoperative morbidity and mortality [3, 12]. However, infectious complications are often diagnosed only after the patient develops clinical symptoms, thus requiring major clinical interventions such as reoperation 
and/or intensive care. Therefore, early detection of these complications through a prompt, intensive clinical search may be of considerable clinical benefit.

This retrospective analysis was conducted to investigate predictive factors for postoperative infectious complications, including systemic inflammatory markers such as C-reactive protein (CRP) and white blood cell (WBC) count, and to define relevant clinical parameters for early detection of these complications in patients who have undergone gastric cancer resection.

\section{Patients and methods}

\section{Study population}

We retrospectively reviewed the records of 417 consecutive patients who underwent elective gastrectomy for primary gastric cancer between January 1, 2009 and December 31, 2012 at Osaka National Hospital. All the patients received perioperative management by clinical path, which routinely included antibiotic prophylaxis $(1 \mathrm{~g}$ intravenous cefazolin $30 \mathrm{~min}$ before surgical incision, repeated every $3 \mathrm{~h}$ during surgery) and blood samplings on postoperative days (PODs) 1 and 3. Data were collected on the following variables: age, sex, preoperative body mass index (BMI), serum albumin (Alb) level, performance status (PS) based on the Eastern Cooperative Oncology Group (ECOG) scale, physical status based on the American Society of Anesthesiologists (ASA) classification, initial clinical stage, the presence of neoadjuvant chemotherapy, surgical procedures (mode of approach, type of resection, degree of lymph node dissection, and presence of combined splenectomy and/or distal pancreatectomy), operation time, intraoperative blood loss, serum CRP level and WBC count after surgery, and postoperative complications according to the Clavien-Dindo classification [13, 14].

\section{Outcome measures}

Surgical and nonsurgical complications occurring from the start of surgery to hospital discharge were documented prospectively. The following postoperative infectious complications were analyzed: abdominal abscess (collection of pus confirmed by percutaneous drainage), pancreatic fistula (drain output of any measurable volume of fluid on or after POD 3 with an amylase content greater than three times the serum amylase level [15]), anastomotic leakage (positive-contrast swallow test), wound infection (purulent exudate in the wound with positive bacterial culture), and pneumonia (clinical signs of pneumonia with radiographic evidence and positive sputum culture or bronchoalveolar lavage). Serum levels of CRP and WBC counts were measured on PODs 1 and 3.

Statistical analysis

SPSS statistical software version 19.0 (IBM SPSS, Chicago, IL, USA) was used for all statistical analyses, and a two-sided $P$ value $<0.05$ was considered significant. Continuous data are presented as mean \pm standard deviation (SD) or median with range, as indicated. The MannWhitney test and chi-square test were employed to evaluate differences in continuous and categorical variables, respectively. Diagnostic accuracy was determined by the area under the receiver operating characteristic (ROC) curve (AUC) [16-18]. An AUC $>0.8$ was considered to indicate high diagnostic accuracy, given that at least $80 \%$ of the patients with the disease were classified correctly [19]. AUCs were computed using the nonparametric trapezoidal method, with their $95 \%$ confidence intervals (CIs) obtained using the approach of DeLong et al. [20]. The optimal cutoff values were determined by maximizing Youden's index (sensitivity + specificity -1 ). Univariate and multivariate logistic regression analyses were used to identify clinical risk factors for postoperative infectious complications of grade III or more according to the Clavien-Dindo classification.

\section{Results}

\section{Patient characteristics}

Patient characteristics are summarized in Table 1. The study population consisted of 140 women and 277 men with a mean age of $66.1 \pm 11.3$ years. The preoperative mean BMI and Alb level of all patients were $22.1 \pm 3.5 \mathrm{~kg} / \mathrm{m}^{2}$ and $4.1 \pm 0.5 \mathrm{~g} / \mathrm{dl}$, respectively. Four hundred six patients had a PS of 0 or 1 on the ECOG scale, and 361 patients had an ASA-graded physical status of 1 or 2. Neoadjuvant chemotherapy was administered to 31 patients, and 212 patients had disease of clinical stage I. The majority of the patients underwent open gastrectomy, and 152 patients received total gastrectomy. Three hundred and ten patients underwent D2 or more lymphadenectomy, with combined splenectomy and distal pancreatectomy performed in 46 and 8 patients, respectively. The median operation time was 252 (range 124-668) minutes, with a median blood loss of 200 (range 10-1935) ml. Postoperative infectious complications of grade III or greater according to the Clavien-Dindo classification $[13,14]$ were observed in 44 patients $(10.6 \%, 95 \%$ CI 7.6-13.5\%), involving anastomotic leakage in 19, pancreatic fistula in 6 , abdominal abscess in 10 , wound infection in 3 , and 
Table 1 Patient characteristics $(n=417)$

$B M I$ body mass index, $E C O G$ Eastern Cooperative Oncology Group, $P S^{l}$ performance status, ASA American Society of Anesthesiologists, $P S^{2}$ physical status

\begin{tabular}{|c|c|}
\hline Characteristic & $n=417$ \\
\hline Age (years) & $66.1 \pm 11.3$ \\
\hline \multicolumn{2}{|l|}{ Sex } \\
\hline Male & 277 \\
\hline Female & 140 \\
\hline BMI $\left(\mathrm{kg} / \mathrm{m}^{2}\right)$ & $22.1 \pm 3.5$ \\
\hline Preoperative serum albumin ( $\mathrm{g} / \mathrm{dl})$ & $4.1 \pm 0.5$ \\
\hline ECOG-PS $^{1} 0 / 1 / 2 / 3$ & $365 / 41 / 8 / 3$ \\
\hline ASA-PS $^{2} 1 / 2 / 3$ & $105 / 256 / 56$ \\
\hline Clinical stage I/II/III/IV & $212 / 73 / 85 / 47$ \\
\hline \multicolumn{2}{|l|}{ Neoadjuvant chemotherapy } \\
\hline Present & 31 \\
\hline Absent & 386 \\
\hline \multicolumn{2}{|l|}{ Mode of surgical approach } \\
\hline Laparoscopic & 50 \\
\hline Open & 367 \\
\hline \multicolumn{2}{|l|}{ Type of resection } \\
\hline Distal gastrectomy & 233 \\
\hline Proximal gastrectomy & 32 \\
\hline Total gastrectomy & 152 \\
\hline Degree of lymph node dissection (D) $0 / 1 / 2 / 3$ & $8 / 99 / 295 / 15$ \\
\hline \multicolumn{2}{|l|}{ Combined resection } \\
\hline Splenectomy & 46 \\
\hline Distal pancreatectomy & 8 \\
\hline Operation time (min) & $252(124-668)$ \\
\hline Blood loss (ml) & $200(10-1935)$ \\
\hline \multicolumn{2}{|c|}{ Postoperative infectious complications according to the Clavien-Dindo classification } \\
\hline None or $<$ grade III & 373 \\
\hline$\geq$ grade III & 44 \\
\hline
\end{tabular}

pneumonia in 6. Five patients died during hospitalization, resulting in an in-hospital mortality rate of $1.2 \%(95 \% \mathrm{CI}$ $0.15-2.57 \%$ ). Cause of death was anastomotic leakage in 2 , pneumonia in 2, and abdominal abscess in 1 .

Associations of postoperative CRP level and WBC count with infectious complications

Chronological changes in CRP and WBC values after gastrectomy are demonstrated in Fig. 1a and b. A sharp and persistent rise in CRP was observed until POD 3 in patients with postoperative infectious complications of grade $\geq$ III, at which point the CRP level was significantly higher than for patients with postoperative infectious complications of grade $<$ III. In contrast, WBC reached its highest level on POD 1 and declined thereafter, showing a similar tendency between patients with and without postoperative infectious complications of grade $\geq$ III.

When following the CRP values from POD 3 through POD7, they were $17.54 \pm 9.18 \mathrm{mg} / \mathrm{dl}$ on POD 5 and $11.51 \pm 7.06 \mathrm{mg} / \mathrm{dl}$ on POD 7 in patients with postoperative infectious complications of grade $\geq$ III, and $9.50 \pm 5.42 \mathrm{mg} /$ $\mathrm{dl}$ and $4.34 \pm 4.63 \mathrm{mg} / \mathrm{dl}$ on PODs 5 and 7, respectively, in patients with postoperative infectious complications of grade $\leq$ III. There was a statistically significant difference in CRP levels on both PODs $5(p \leq 0.001)$ and $7(p \leq 0.001)$ between patients with and without postoperative infectious complications of grade $\geq$ III.

The diagnostic accuracy of CRP and WBC on POD 3 for the occurrence of postoperative infectious complications of grade $\geq$ III was evaluated by the AUC, as shown in Fig. 2a and $b$, respectively. CRP on POD 3 had superior diagnostic accuracy (AUC 0.802, $95 \%$ CI 0.735-0.870), with a calculated optimal cutoff value of $17.7 \mathrm{mg} / \mathrm{dl}$, compared to WBC on POD 3 (AUC 0.680, $95 \%$ CI 0.590-0.770).

Predictive factors for postoperative infectious complications of grade III or more

The results of univariate and multivariate analyses of various clinical factors, such as age, sex, preoperative BMI, Alb, ECOG-PS, ASA physical status, clinical stage, 
(a)

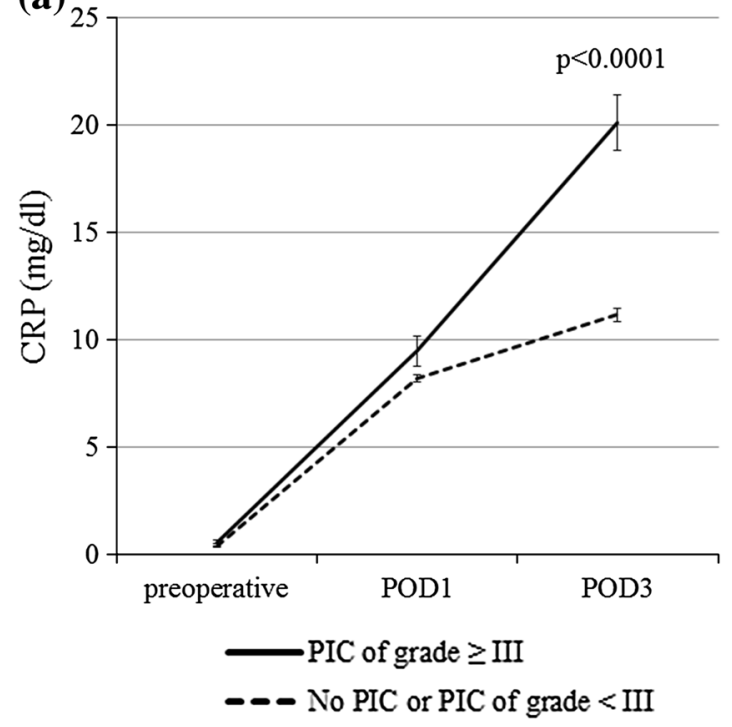

(b)

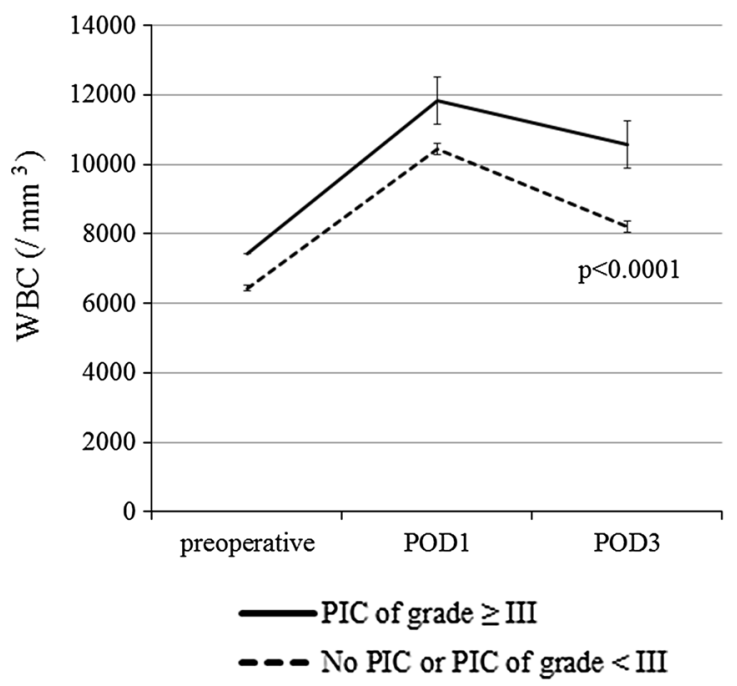

Fig. 1a-b Postoperative chronological changes in CRP levels (a) and WBC counts (b). PIC postoperative infectious complication, POD postoperative day
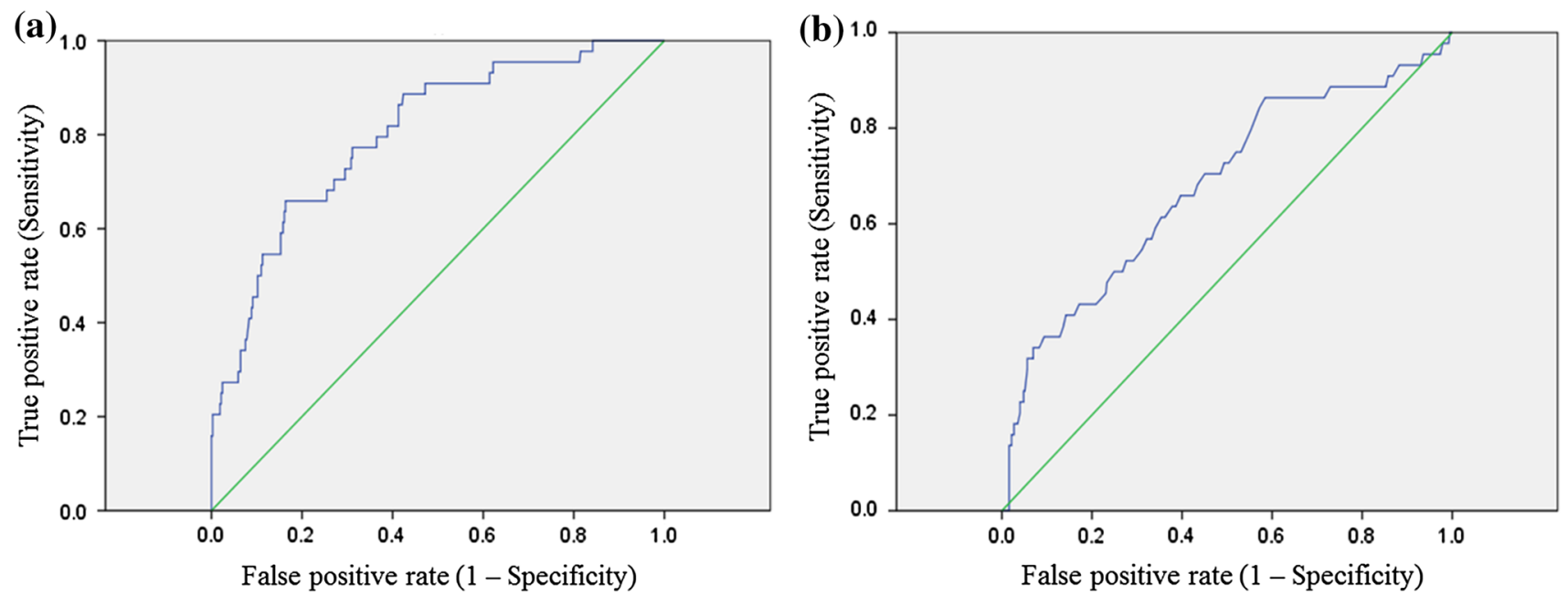

Fig. 2a-b ROC curves for the diagnostic accuracy of CRP (a) and WBC (b) on POD 3 in predicting postoperative infectious complications of grade $\geq$ III

presence of neoadjuvant chemotherapy, surgical procedures (mode of approach, type of resection, degree of lymph node dissection, and presence of combined splenectomy and/or distal pancreatectomy), operation time, intraoperative blood loss, and CRP on POD 3 for postoperative infectious complications of grade $\geq$ III are summarized in Table 2. Among these, clinical stage of II or more [odds ratio (OR) 4.445, $95 \%$ CI 1.478-15.881], operation time $\geq 250 \mathrm{~min} \quad(\mathrm{OR} 3.638,95 \% \mathrm{CI}$ $1.449-10.137$ ), and CRP on POD 3 of $17.7 \mathrm{mg} / \mathrm{dl}$ or greater (OR 8.094, $95 \%$ CI 3.568-19.342) were identified as significant independent predictive factors for infectious complications after gastrectomy.

\section{Discussion}

Overall morbidity and mortality rates after gastric cancer resection were most recently reported to be 14.2 and $1.1 \%$ for distal gastrectomy and 21.5 and $2.3 \%$ for total gastrectomy, respectively, in a nationwide survey in Japan [21]. These results are consistent with the findings from previous East Asian reports [4-6] showing morbidity and mortality rates of $17.4-24.5 \%$ and $0.6-0.8 \%$, respectively, while higher overall morbidity rates of $13.6-46 \%$ and mortality rates of $0.6-13 \%$ have been demonstrated after radical gastrectomy in the West [7-11]. Infectious complications such as pancreatic fistula, anastomotic 
Table 2 Univariate and multivariate analyses of clinical factors for postoperative infectious complications of grade $\geq$ III

\begin{tabular}{|c|c|c|c|c|c|c|}
\hline \multirow[t]{2}{*}{ Characteristics } & \multicolumn{3}{|c|}{ Univariate analysis } & \multicolumn{3}{|c|}{ Multivariate analysis } \\
\hline & No. of patients & $\begin{array}{l}\text { No. of patients with } \\
\text { PICs of grade } \geq \text { III }\end{array}$ & $P$ value & Odds ratio & $95 \% \mathrm{CI}$ & $P$ value \\
\hline \multicolumn{7}{|l|}{ Age (years) } \\
\hline$<75$ & 322 & 28 & 0.023 & 1 & $0.784-4.929$ & 0.146 \\
\hline$\geq 75$ & 95 & 16 & & 1.979 & & \\
\hline \multicolumn{7}{|l|}{ Sex } \\
\hline Female & 140 & 9 & 0.051 & 1 & $0.463-3.175$ & 0.737 \\
\hline Male & 277 & 35 & & 1.176 & & \\
\hline \multicolumn{7}{|l|}{ BMI $\left(\mathrm{kg} / \mathrm{m}^{2}\right)$} \\
\hline$<25$ & 341 & 32 & 0.100 & 1 & $0.404-2.878$ & 0.839 \\
\hline$\geq 25$ & 76 & 12 & & 1.106 & & \\
\hline \multicolumn{7}{|c|}{ Preoperative serum albumin $(\mathrm{g} / \mathrm{dl})$} \\
\hline$\geq 3.5$ & 366 & 37 & 0.431 & 1 & $0.263-2.555$ & 0.817 \\
\hline$<3.5$ & 51 & 7 & & 0.877 & & \\
\hline \multicolumn{7}{|l|}{ ECOG-PS $^{1}$} \\
\hline 0,1 & 406 & 40 & 0.020 & 1 & $0.488-15.062$ & 0.236 \\
\hline 2,3 & 11 & 4 & & 2.822 & & \\
\hline \multicolumn{7}{|l|}{ ASA-PS $^{2}$} \\
\hline 1,2 & 361 & 37 & 0.610 & 1 & $0.178-1.682$ & 0.326 \\
\hline 3 & 56 & 7 & & 0.581 & & \\
\hline \multicolumn{7}{|l|}{ Clinical stage } \\
\hline I & 212 & 7 & $<0.001$ & 1 & $1.478-15.881$ & 0.006 \\
\hline II, III, IV & 205 & 37 & & 4.445 & & \\
\hline \multicolumn{7}{|c|}{ Neoadjuvant chemotherapy } \\
\hline Absent & 386 & 39 & 0.293 & 1 & $0.246-3.175$ & 0.920 \\
\hline Present & 31 & 5 & & 0.937 & & \\
\hline \multicolumn{7}{|c|}{ Mode of surgical approach } \\
\hline Laparoscopic & 50 & 2 & 0.108 & 1 & $0.198-12.171$ & 0.766 \\
\hline Open & 367 & 42 & & 1.347 & & \\
\hline \multicolumn{7}{|c|}{ Type of resection } \\
\hline Partial & 265 & 18 & 0.001 & 1 & $0.455-3.134$ & 0.702 \\
\hline Total & 152 & 26 & & 1.205 & & \\
\hline \multicolumn{7}{|c|}{ Degree of lymph node dissection (D) } \\
\hline 0,1 & 107 & 7 & 0.117 & 1 & $0.289-3.162$ & 0.878 \\
\hline 2,3 & 310 & 37 & & 0.911 & & \\
\hline \multicolumn{7}{|c|}{ Combined splenectomy and/or distal pancreatectomy } \\
\hline Absent & 363 & 29 & $<0.001$ & 1 & $0.681-5.815$ & 0.211 \\
\hline Present & 54 & 15 & & 1.963 & & \\
\hline \multicolumn{7}{|c|}{ Operation time (min) } \\
\hline$<250$ & 204 & 7 & $<0.001$ & 1 & $1.449-10.137$ & 0.005 \\
\hline$\geq 250$ & 213 & 37 & & 3.638 & & \\
\hline \multicolumn{7}{|l|}{ Blood loss (ml) } \\
\hline$<200$ & 209 & 10 & $<0.001$ & 1 & $0.597-3.960$ & 0.393 \\
\hline$\geq 200$ & 208 & 34 & & 1.497 & & \\
\hline \multicolumn{7}{|c|}{ CRP on POD3 (mg/dL) } \\
\hline$<17.7$ & 327 & 15 & $<0.001$ & 1 & $3.568-19.342$ & $<0.001$ \\
\hline$\geq 17.7$ & 90 & 29 & & 8.094 & & \\
\hline
\end{tabular}

BMI body mass index, ECOG Eastern Cooperative Oncology Group, $P S^{1}$ performance status, $A S A$ American Society of Anesthesiologists, $P S^{2}$ physical status, PICs postoperative infectious complications, $C I$ confidence interval 
leakage, and abdominal abscess represent major causes of postoperative morbidity and mortality. Postoperative infectious complications worsen early surgical outcomes, leading to longer hospital stays and higher medical costs. Therefore, early identification of patients at risk for infectious complications is undoubtedly of high clinical value, as it allows clinicians to initiate therapeutic surgical or medical interventions in potentially septic patients to avert life-threatening conditions. In addition, postoperative intra-abdominal infectious complications have been shown to adversely affect overall and relapse-free survival in patients undergoing curative gastrectomy for gastric cancer [22-24]. Thus, postoperative infectious complications can be catastrophic in patients undergoing gastric cancer resection, in terms of both short- and long-term outcomes.

There is presently no reliable diagnostic test with sufficient accuracy to detect postoperative infectious complications at an early stage. There are several biochemical markers of the acute systemic inflammatory response, including CRP and WBC, and several recent studies have suggested a possible role for CRP in predicting the likelihood of infectious complications after gastrointestinal cancer surgery [19, 25-31], as shown in Table 3. These studies have proposed that an abnormally elevated CRP level on POD 3 or 4 or persistent elevation of CRP may be a useful predictor of infectious complications. Of note, ROC analysis with an AUC $\geq 0.8$ indicated that relatively similar CRP levels ranging from 12.3 to $19.0 \mathrm{mg} / \mathrm{dl}$ provided the best cutoff to balance sensitivity and specificity in a variety of gastrointestinal cancer surgeries. Our CRP cutoff of $17.7 \mathrm{mg} / \mathrm{dl}$ on POD 3 corresponds well with the cutoff values of the aforementioned studies, although it was not identical to all of them. The differences are likely to be due to different types of cancer, wide-ranging sample sizes, and varying criteria for the diagnosis of infectious complications. These findings suggest the universality of CRP as an early indicator of postoperative infectious complications.
With regard to the diagnostic value of postoperative CRP concentrations in predicting infectious complications, particularly after gastric cancer resection, there has been no report focusing on patients after gastric cancer resection, though there are limited reports with relatively small sample sizes of 136-210 patients [19, 31] relating to gastroesophageal junction cancer as well as gastric cancer. Additionally, the sample size of the present study, at 417 patients, is currently the largest in the literature on esophagogastric cancer surgery [19, 31], as shown in Table 3.

Although D2 gastrectomy is now recommended as the standard surgical procedure for patients with resectable gastric cancer in Europe [32, 33] and the United States [34], as well as in East Asia [35], various degrees of lymphadenectomy were performed in previous Western studies [19, 31] investigating CRP values following esophagogastric cancer surgery. Interestingly, however, those two studies $[19,31]$ were similar to our own in terms of the CRP cutoff value identified as the best predictor of postoperative infectious complications, which suggests that optimal predictive value of CRP was only minimally affected by differing amounts of surgical stress and varying incidences of postoperative morbidity in relation to the specific lesions being treated.

As for the impact of initial surgical stress on CRP values on POD 3, there were no significant differences between laparoscopic and open surgery $(p=0.2801)$, distal and total gastrectomy $(p=0.5597)$, and D1 and D2 lymph node dissection $(p=0.3336)$ in our patients. Furthermore, when analyzing the predictive factors for postoperative infectious complications of grade $\geq$ III according to the type of resection, only CRP on POD 3 of $17.7 \mathrm{mg} / \mathrm{dl}$ or greater (OR 6.333, 95 \% CI 1.567-29.336) was identified as a significant predictive factor after distal gastrectomy with D2 dissection $(n=161)$, while operation time $\geq 250 \min$ (OR 5.484, $95 \%$ CI 1.215-39.933) and CRP on

Table 3 Literature examining the value of CRP for predicting postoperative infectious complications following gastrointestinal cancer surgery

\begin{tabular}{|c|c|c|c|c|c|c|c|}
\hline Study & Type of cancer & Patients $(n)$ & POD & CRP cutoff (mg/dL) & Sensitivity (\%) & Specificity (\%) & AUC \\
\hline Welsch et al. [25] & $\mathrm{R}$ & 48 & 3 & 14.0 & 80 & 81 & 0.88 \\
\hline Welsch et al. [26] & $\mathrm{P}$ & 688 & 4 & 14.0 & 70 & 87 & 0.86 \\
\hline Korner et al. [27] & $\mathrm{CR}$ & 231 & 3 & 19.0 & 82 & 73 & 0.82 \\
\hline Mackay et al. [28] & $\mathrm{CR}$ & 160 & 4 & 14.5 & 85 & 86 & 0.87 \\
\hline Warschkow et al. [29] & $\mathrm{CR}$ & 1187 & 4 & 12.3 & 66 & 77 & 0.76 \\
\hline Plat et al. [30] & $\mathrm{CR}$ & 454 & 3 & 17.0 & 74 & 75 & 0.80 \\
\hline Dutta et al. [19 & OG & 136 & 3 & 18.0 & 52 & 64 & 0.81 \\
\hline Warschkow et al. [31] & OG & 210 & 4 & 14.1 & 78 & 70 & 0.77 \\
\hline This study & $\mathrm{G}$ & 417 & 3 & 17.7 & 66 & 84 & 0.80 \\
\hline
\end{tabular}

$R$ rectal, $P$ pancreatic, $C R$ colorectal, $O G$ esophagogastric, $P O D$ postoperative day, $C R P$ C-reactive protein, $A U C$ area under the receiver operating characteristic curve 
POD 3 of $17.7 \mathrm{mg} / \mathrm{dl}$ or greater (OR7.518, $95 \% \mathrm{CI}$ 2.015-31.840) were identified as significant predictive factors for postoperative infectious complications of grade $\geq$ III after D2 total gastrectomy ( $n=134)$.

In our cohort, postoperative infectious complications of grade III or greater occurred in 44 patients $(10.6 \%, 95 \%$ CI 7.6-13.5\%). Recent East Asian studies have demonstrated similar $\geq$ grade 3 infectious complication rates of 8.2-9.9\% [36, 37] after gastrectomy, suggesting that our patients were not exceptional in this regard. Therefore, we believe that our findings could be highly relevant for, and might be generalizable to, patients undergoing gastrectomy for gastric cancer. Additionally, in these 44 patients, the median day of diagnosis of postoperative infectious complications was POD 6 , with anastomotic leakage $(n=19)$ being detected on POD 7 at median, pancreatic fistula $(n=6)$ on POD 3 , abdominal abscess $(n=10)$ on POD 7 , wound infection $(n=3)$ on POD 7 , and pneumonia $(n=6)$ on POD 6 . These findings suggest that elevated CRP levels on POD 3 preceded the development of infectious complications by 3 days. During these 3 days, preemptive antibiotic use or surgical intervention through further diagnostic measures such as thoracic X-rays, upper gastrointestinal series, or CT scans could improve patient outcomes. However, the impact on morbidity and mortality of early intervention based on postoperative monitoring of CRP concentrations should be further investigated in a prospective study.

As shown in Fig. 2a, CRP on POD 3 had superior diagnostic accuracy for postoperative infectious complications (AUC 0.802, $95 \%$ CI 0.735-0.870), with a calculated optimal cutoff value of $17.7 \mathrm{mg} / \mathrm{dl}$. Using this cutoff value, the sensitivity was $0.66 \quad(95 \%$ CI 0.524-0.774), and the specificity was 0.84 (95\% CI 0.821-0.850), which corresponded well with the results of previous studies as shown in Table 3. These results suggest a moderate diagnostic accuracy of CRP for detecting postoperative infectious complications. In addition, in this study, the estimated optimal cutoff value of $17.7 \mathrm{mg} / \mathrm{dl}$ for CRP on POD 3 yielded a positive predictive value (PPV) of 0.32 (95\% CI $0.256-0.378$ ) and a negative predictive value (NPV) of 0.95 (95\% CI 0.936-0.970), which were in accordance with the PPV of 0.50 (95\% CI 0.37-0.63) and the NPV of 0.89 (95\% CI $0.77-0.95$ ) reported by Warschkow et al. [31] following gastroesophageal cancer surgery. The high NPV of 0.95 suggests that the development of postoperative infectious complications can be ruled out when the CRP value on POD 3 is $17.7 \mathrm{mg} / \mathrm{dl}$ or less, whereas the PPV of 0.32 is too low to rule in postoperative infectious complications. Due to this moderate diagnostic performance, CRP should not be used as a "black-andwhite" criterion with sufficiently high performance to correctly predict infectious complications in clinical practice. CRP levels must be interpreted in the context of the whole clinical picture. Thus, elevated CRP levels $\geq 17.7 \mathrm{mg} / \mathrm{dl}$ on POD 3 should raise the degree of suspicion for infectious complications after gastrectomy. The reliable ability to predict an uncomplicated postoperative course would certainly be of significant value to clinicians when incorporated into early discharge criteria.

Despite its moderate accuracy, CRP of $17.7 \mathrm{mg} / \mathrm{dl}$ or greater on POD 3 (OR 8.094, $95 \%$ CI 3.568-19.342) was identified as a significant independent predictive factor for postoperative infectious complications after gastrectomy, as shown in Table 2. To the best of our knowledge, this is the first study proving that CRP level in the early postoperative period is an independent predictor for postoperative infectious complications, at least in the field of gastric cancer surgery, since examinations of the relationship of CRP level with postoperative infectious complications are scarce [19, 31], as shown in Table 3. Patients with elevated CRP levels $\geq 17.7 \mathrm{mg} / \mathrm{dl}$ on POD 3 should be screened for potential infectious processes, though the discriminatory performance is insufficient to precisely predict infectious complications in clinical practice. As a consequence, CRP is nonspecific but helpful and relevant to clinical assessment in the postoperative setting after gastric cancer resection.

Other systemic inflammatory markers such as WBC count and body temperature have been reported to have poor diagnostic accuracy for detecting postoperative infectious complications, as they do not differ significantly from uneventful courses until later stages [26, 27]. This is in contrast to $\mathrm{CRP}$, which demonstrated consistent increases on PODs 2-4. In addition, both WBC count and body temperature failed to predict unfavorable outcomes as precisely as increases in CRP did [19, 25, 26, 29, 30]. The results of the present study are consistent with previous studies that highlighted the superiority of elevated CRP level over WBC count and body temperature in predicting the development of postoperative infectious complications. Although the reasons for this discrepancy in relative predictive value between $\mathrm{CRP}$ and $\mathrm{WBC}$ count remain unclear, it might be speculated that CRP is more sensitive to the presence of infection because it plays an important direct role in innate immunity as an early defense against infection, assisting complement binding to foreign and damaged cells and enhancing phagocytosis by macrophages [19]. In addition, the short CRP half-life of $19 \mathrm{~h}$ makes it an optimal marker to detect the inflammatory response during postoperative recovery.

In conclusion, we investigated predictive factors for postoperative infectious complications and identified an elevated CRP level $\geq 17.7 \mathrm{mg} / \mathrm{dl}$ on POD 3 as a significant predictor for infectious complications after gastrectomy. To the best of our knowledge, this is the first Asian study 
examining the relationship of CRP values with postoperative infectious complications, and our sample size of 417 patients was the largest thus far in the literature on esophagogastric cancer [19, 31], as shown in Table 3. However, the limitations of this study, which include its retrospective and single-institution nature, need to be taken into account before generalizing its results to daily clinical practice until prospective, multicenter validation is available. Furthermore, prospective studies should investigate whether early diagnostic or therapeutic approaches based on elevated CRP level on POD 3 actually lead to earlier detection of postoperative infectious complications, improved outcomes, and reduced morbidity after gastrectomy. Nonetheless, we believe that our findings will help physicians predict patients' postoperative courses and facilitate decision-making regarding prompt, comprehensive clinical searches for postoperative infectious complications.

\section{References}

1. Ferlay J, Shin HR, Bray F, Forman D, Mathers C, Parkin DM. Estimates of worldwide burden of cancer in 2008: GLOBOCAN 2008. Int J Cancer. 2010;127:2893-917.

2. Jemal A, Bray F, Center MM, Ferlay J, Ward E, Forman D. Global cancer statistics. CA Cancer J Clin. 2011;61:69-90.

3. Sah BK, Zhu ZG, Chen MM, Yan M, Yin HR, Zhen LY. Gastric cancer surgery and its hazards: postoperative infection is the most important complication. Hepatogastroenterol. 2008;55:2259-63.

4. Sano T, Sasako M, Yamamoto S, Nashimoto A, Kurita A, Hiratsuka $\mathrm{M}$, et al. Gastric cancer surgery: morbidity and mortality results from a prospective randomized controlled trial comparing D2 and extended para-aortic lymphadenectomy-Japan Clinical Oncology Group study 9501. J Clin Oncol. 2004;22:2767-73.

5. Park DJ, Lee HJ, Kim HH, Yang HK, Lee KU, Choe KJ. Predictors of operative morbidity and mortality in gastric cancer surgery. Br J Surg. 2005;92:1099-102.

6. Jung MR, Park YK, Seon JW, Kim KY, Cheong O, Ryu SY. Definition and classification of complications of gastrectomy for gastric cancer based on the Accordion Severity Grading System. World J Surg. 2012;36:2400-11.

7. Bonenkamp JJ, Songun I, Hermans J, Sasako M, Welvaart K, Plukker JT, et al. Randomised comparison of morbidity after D1 and D2 dissection for gastric cancer in 996 Dutch patients. Lancet. 1995;345:745-8.

8. Cuschieri A, Fayers P, Fielding J, Craven J, Bancewicz J, Joypaul $\mathrm{V}$, et al. Postoperative morbidity and mortality after D1 and D2 resections for gastric cancer: preliminary results of the MRC randomised controlled surgical trial. The Surgical Cooperative Group. Lancet. 1996;347:995-9.

9. Degiuli M, Sasako M, Calgaro M, Garino M, Rebecchi F, Mineccia M, et al. Morbidity and mortality after D1 and D2 gastrectomy for cancer: interim analysis of the Italian Gastric Cancer Study Group (IGCSG) randomised surgical trial. Eur J Surg Oncol. 2004;30:303-8.

10. Marrelli D, Pedrazzani C, Neri A, Corso G, DeStefano A, Pinto E, et al. Complications after extended (D2) and superextended (D3) lymphadenectomy for gastric cancer: analysis of potential risk factors. Ann Surg Oncol. 2007;14:25-33.
11. Persiani R, Antonacci V, Biondi A, Rausei S, La Greca A, Zoccali $\mathrm{M}$, et al. Determinants of surgical morbidity in gastric cancer treatment. J Am Coll Surg. 2008;207:13-9.

12. Sah BK, Chen MM, Yan M, Zhu ZG. Reoperation for early postoperative complications after gastric cancer surgery in a Chinese hospital. World J Gastroenterol. 2010;16:98-103.

13. Dindo D, Demartines N, Clavien PA. Classification of surgical complications: a new proposal with evaluation in a cohort of 6336 patients and results of a survey. Ann Surg. 2004;240:205-13.

14. Clavien PA, Barkun J, de Oliveira ML, Vauthey JN, Dindo D, Schulick RD, et al. The Clavien-Dindo classification of surgical complications: five-year experience. Ann Surg. 2009;250:187-96.

15. Bassi C, Dervenis C, Butturini G, Fingerhut A, Yeo C, Izbicki J, International Study Group on Pancreatic Fistula Definition, et al. Postoperative pancreatic fistula: an international study group (ISGPF) definition. Surgery. 2005;138:8-13.

16. Robertson EA, Zweig MH. Use of receiver operating characteristic curves to evaluate the clinical performance of analytical systems. Clin Chem. 1981;27:1569-74.

17. Zweig MH, Campbell G. Receiver-operating characteristic (ROC) plots: a fundamental evaluation tool in clinical medicine. Clin Chem. 1993;39:561-77.

18. Soreide K. Receiver-operating characteristic curve analysis in diagnostic, prognostic and predictive biomarker research. J Clin Pathol. 2009;62:1-5.

19. Dutta S, Fullarton GM, Forshaw MJ, Horgan PG, McMillan DC. Persistent elevation of C-reactive protein following esophagogastric cancer resection as a predictor of postoperative surgical site infectious complications. World J Surg. 2011;35:1017-25.

20. DeLong ER, DeLong DM, Clarke-Pearson DL. Comparing the areas under two or more correlated receiver operating characteristic curves: a nonparametric approach. Biometrics. 1988;44:837-45.

21. Watanabe M, Miyata H, Gotoh M, Baba H, Kimura W, Tomita N, et al. Total gastrectomy risk model: data from 20,011 Japanese patients in a nationwide internet-based database. Ann Surg. 2014;260:1034-9.

22. Tsujimoto H, Ichikura T, Ono S, Sugasawa H, Hiraki S, Sakamoto $\mathrm{N}$, et al. Impact of postoperative infection on long-term survival after potentially curative resection for gastric cancer. Ann Surg Oncol. 2009;16:311-8.

23. Sierzega M, Kolodziejczyk P, Kulig J, Polish Gastric Cancer Study Group. Impact of anastomotic leakage on long-term survival after total gastrectomy for carcinoma of the stomach. Br J Surg. 2010;97:1035-42.

24. Tokunaga M, Tanizawa Y, Bando E, Kawamura T, Terashima M. Poor survival rate in patients with postoperative intra-abdominal infectious complications following curative gastrectomy for gastric cancer. Ann Surg Oncol. 2013;20:1575-83.

25. Welsch T, Müller SA, Ulrich A, Kischlat A, Hinz U, Kienle P, et al. C-reactive protein as early predictor for infectious postoperative complications in rectal surgery. Int $\mathbf{J}$ Colorectal Dis. 2007;22:1499-507.

26. Welsch T, Frommhold K, Hinz U, Weigand MA, Kleeff J, Friess $\mathrm{H}$, et al. Persisting elevation of $\mathrm{C}$-reactive protein after pancreatic resections can indicate developing inflammatory complications. Surgery. 2008;143:20-8.

27. Kørner H, Nielsen HJ, Søreide JA, Nedrebø BS, Søreide K, Knapp JC. Diagnostic accuracy of C-reactive protein for intraabdominal infections after colorectal resections. J Gastrointest Surg. 2009;13:1599-606.

28. MacKay GJ, Molloy RG, O'Dwyer PJ. C-reactive protein as a predictor of postoperative infective complications following elective colorectal resection. Colorectal Dis. 2011;13:583-7. 
29. Warschkow R, Tarantino I, Torzewski M, Näf F, Lange J, Steffen T. Diagnostic accuracy of C-reactive protein and white blood cell counts in the early detection of inflammatory complications after open resection of colorectal cancer: a retrospective study of 1,187 patients. Int J Colorectal Dis. 2011;26:1405-13.

30. Platt JJ, Ramanathan ML, Crosbie RA, Anderson JH, McKee RF, Horgan PG, et al. C-reactive protein as a predictor of postoperative infective complications after curative resection in patients with colorectal cancer. Ann Surg Oncol. 2012;19:4168-77.

31. Warschkow R, Tarantino I, Ukegjini K, Beutner U, Müller SA, Schmied BM, et al. Diagnostic study and meta-analysis of $\mathrm{C}$-reactive protein as a predictor of postoperative inflammatory complications after gastroesophageal cancer surgery. Langenbecks Arch Surg. 2012;397:727-36.

32. Songun I, Putter H, Kranenbarg EM, Sasako M, van de Velde CJ. Surgical treatment of gastric cancer: 15-year follow-up results of the randomized nationwide Dutch D1D2 trial. Lancet Oncol. 2010;11:439-49.
33. Okines A, Verheij M, Allum W, Cunningham D, Cervantes A, ESMO Guidelines Working Group. Gastric cancer: ESMO Clinical Practice Guidelines for diagnosis, treatment and followup. Ann Oncol. 2010;21(suppl 5):v50-4.

34. NCCN clinical practice guidelines in oncology: gastric cancer. Version 2. Fort Washington: NCCN; 2011. http://www.ncen.org.

35. Sasako M, Sano T, Yamamoto S, Kurokawa Y, Nashimoto A, Kurita A, Japan Clinical Oncology Group, et al. D2 lymphadenectomy alone or with para-aortic nodal dissection for gastric cancer. N Engl J Med. 2008;359:453-62.

36. Lee KG, Lee HJ, Yang JY, Oh SY, Bard S, Suh YS, et al. Risk factors associated with complication following gastrectomy for gastric cancer: retrospective analysis of prospectively collected data based on the Clavien-Dindo system. J Gastrointest Surg. 2014;18:1269-77.

37. Miki Y, Tokunaga M, Tanizawa Y, Bando E, Kawamura T, Terashima M. Perioperative risk assessment for gastrectomy by Surgical Apgar Score. Ann Surg Oncol. 2014;21:2601-7. 